\title{
Fecal Calprotectin Level of Breast Milk-Formula vs Formula Feeding in Preterm and Low Birth Weight Neonates with Necrotizing Enterocolitis
}

\author{
Ditya Arisanti ${ }^{1,2} *$, Satrio Wibowo ${ }^{1,2}$ \\ ${ }^{1}$ Department of Pediatric, Saiful Anwar Public Hospital, Malang 65145, Indonesia \\ ${ }^{2}$ Faculty of Medicine, Brawijaya University, Malang 65145, Indonesia
}

Article history:

Submission February 2016

Revised July 2018

Accepted August 2018

*Corresponding author:

E-mail: dityaarisanti_dr@yahoo.com

\begin{abstract}
Necrotizing enterocolitis (NE) is inflammatory disease and its prevalence was increase in preterm and low birth weight (LBW) neonates. This study was aimed to investigate the differences of fecal calprotectin level in breast milk-formula vs formula feeding infants in preterm and low birth weight neonates with necrotizing enterocolitis. There are 32 preterm and LBW neonates with NE were divided into two group (breast milk-formula and formula only feeding group). Fecal calprotectin level was measured using ELISA method. This study showed that fecal calprotectin level in breast milk-formula feeding group was insignificantly lower as compared to formula feeding group (independent t-test, $\mathrm{p}=0.503$ ). Further analysis showed that fecal calprotectin level was negatively correlated with patient's outcome (Spearman correlation test, $\mathrm{p}=0.03, \mathrm{r}=0.512$ ). We concluded that fecal calprotectin level in breast milk-formula feeding group was insignificantly lower as compared to formula feeding only group in preterm and low birth weight neonates diagnosed with necrotizing enterocolitis. There was negative correlation between fecal calprotectin level and patient's outcome.
\end{abstract}

Keywords: Breast milk, formula, fecal calprotectin, necrotizing enterocoliti

\section{Introduction}

Necrotizing enterocolitis is one of emergency case in neonates, especially in new born with low birth weight $[1,2]$. The incidence of necrotizing enterocolitis is ranged $1-5 \%$ among 1000 birth rate and increase up to $5-10 \%$ in very low birth weight neonates. Mortality rate of necrotizing enterocolitis is $20-50 \%$ [3,4]. The main risk factor of necrotizing enterocolitis is prematurity and low birth weight $[3,4]$. The others risk factor of necrotizing enterocolitis are administration of enteral nutrition, bacterial colonization, erythrocyte transfusion, prolonged utilization of mechanical ventilator or other ventilation support device [5, 6]. Several studies had been demonstrated the underlying mechanism of necrotizing enterocolitis such as intestinal ischemia, bacterial translocation, septicemia and organ dysfunction [5, 6, 7].

Because of unclear understanding about etio- logic and pathogenesis of necrotizing enterocolitis, the morbidity and mortality of this disease is still high [8]. Recently, there was no consensus concerns about the management of enteral nutrition in order to prevent necrotizing enterocolitis based on time, volume, and type [9]. Breastfeeding had been associated with decreased incidence of necrotizing enterocolitis in preterm neonates [10]. Otherwise, formula feeding was risk factor for developing necrotizing enterocolitis because of its high fatty acid contents which had toxic effect on cells [10].

Many biomarkers had been studied which represented the severity of this disease such as serum amyloid A (SAA), anaphylatoxin (C5a), urinary intestinal fatty acid binding protein (I-FABP), claudin-3, fecal platelet-activating factor (PAF), calprotectin, inter-a-inhibitory protein (IaIp), Creactive protein, and citrulline $[11,12,13]$. Cal-

\section{How to cite:}

Arisanti D, Wibowo S (2019) Fecal Calprotectin Level of Breast Milk-Formula vs Formula Feeding in Preterm and Low Birth Weight Neonates with Necrotizing Enterocolitis. Journal of Tropical Life Science 9 (1): 29 - 33 . doi: 
protectin is peptide which represented local inflammation and apoptosis [14]. Fecal calprotectin had been used as screening tool for intestinal inflammation disease [15]. In certain condition, fecal calprotectin could be used as necrotizing enterocolitis biomarker if its concentrations raised up to $350 \mu \mathrm{g} / \mathrm{g}$ following with intestinal perforation, bloody fecal, and other clinical manifestation representing intestinal injury [16]. This study was aimed to investigate the differences of fecal calprotectin level in breast milk-formula vs formula feeding infants in preterm and low birth weight neonates with necrotizing enterocolitis.

\section{Material and Methods Study design}

This study was cross-sectionally designed to compare fecal calprotectin level of breast milkformula feeding vs formula feeding group in preterm and low birth weight neonates with necrotizing enterocolitis. This study was conducted in neonatology ward of Pediatric Department, Dr. Saiful Anwar Hospital Malang, and Biochemistry Laboratory, Faculty of Medicine, Brawijaya University Malang. This study had been approved by Ethical Committee of Saiful Anwar Hospital Malang, Indonesia. Preterm neonates are defined as neonates which born at gestation week less than 37 weeks. Low birth weight is defined as birth body weight less than 2,500 g. Necrotizing enterocolitis is diagnosed using clinical symptoms (abdominal distension and hematoschezia) and feature of intestinal pneumatosis in plain abdominal radiograph. Formula feeding used in this study was specific formula for low birth weight neonates containing $80 \mathrm{kkal} / 100 \mathrm{~mL}$ calories, $2 \mathrm{~g} / 100 \mathrm{~mL}$ protein, and optimal mineral composition for intrauterine requirements.

\section{Population and subject}

This study contained was sixteen subjects in each group. Inclusion criteria of subject were preterm and low birth weight neonates which had been diagnosed with necrotizing enterocolitis and hospitalized in Saiful Anwar Hospital, any mode of birth delivery (vaginal or abdominal delivery), allowed by his/her parents to join in this study (informed consent). Exclusion criteria of subjects are preterm and low birth weight neonates which need surgical procedure and did not allowed by his/her parents to join in this study.

\section{Fecal sampling}

Fecal sample is obtained with qualified procedure such as stored in special (maintain stable temperature) and clean tube and immediately transported to the laboratory in less than 30 minutes (or could be stored at $-20^{\circ} \mathrm{C}$ ).

\section{Measurements of fecal calprotectin}

Before ELISA procedure performed, fecal sample should be homogenized and extracted using extraction buffer containing $0.1 \mathrm{M}$ Tris, 0.15 $\mathrm{M} \mathrm{NaCl}, 1.0 \mathrm{M}$ urea, $10 \mathrm{mM} \mathrm{CaCl}_{2}, 0.1 \mathrm{M}$ monohydrate citric acid, $5 \mathrm{~g} / \mathrm{L} \mathrm{BSA}, 0.25 \mathrm{mM}$ thimerosal (pH 8.0). as many as $5 \mathrm{~mL}$ extraction buffer is added for each $100 \mathrm{mg}$ sample. After mixing with extraction buffer, sample is shaken for 20 minutes and then centrifuged at $4{ }^{\circ} \mathrm{C}$ for 20 minutes. After centrifugation procedure, sample is ready for ELISA procedure. Basically, sample and calprotectin standard are incubated in microplate which coated with specific antibody for calprotectin. Antibody is conjugated to streptavidin-peroxidase. Streptavidin peroxidase conjugation will react with tetra-methyl-benzidine substrate. This reaction then will be stopped by addition of oxalic acid. Light absorbance is measured using spectrophotometry at wavelength $450 \mathrm{~nm}$. Calprotectin level is converted from absorbance value into concentration using calprotectin standard curve.

\section{Statistical analysis}

Distribution of data calprotectin level was analyzed using Shapiro-Wilk test. Calprotectin level data in combined feeding group was compared to formula feeding only group using independent ttest. Correlation of group and calprotectin level is analyzed using Pearson correlation test. If the data distribution is not normal, comparation and correlation test will be performed using non-parametric test. All the test is performed at confidence interval 95\% using software SPSS version 17.0.

\section{Results and Discussion \\ Characteristics of subjects}

This study involved 32 subjects divided into two groups: preterm and low birth weight neonates diagnosed with necrotizing enterocolitis which receive breast milk-formula feeding and formula feeding. The subject characteristic such as sex, age, gestational age, maternal risk factor, birth weight described in Table 1. Based on sex, data 
Table 1. Characteristic of Subject

\begin{tabular}{|c|c|c|c|}
\hline Characteristic & $\begin{array}{c}\text { Group } 1 \text { Breast milk- } \\
\text { formula feeding }(n=16)\end{array}$ & $\begin{array}{c}\text { Group } 2 \text { Formula feeding } \\
\text { only }(n=16)\end{array}$ & Total \\
\hline \multicolumn{4}{|l|}{ Sex } \\
\hline Male & $6 / 16$ & $8 / 16$ & 14 \\
\hline Female & $10 / 16$ & $8 / 16$ & 18 \\
\hline Onset of NE (mean \pm SD (day)) & $9.31 \pm 4.1$ & $3.75 \pm 1.6$ & \\
\hline Gestational age (mean \pm SD (week)) & $34 \pm 3.2$ & $32.7 \pm 2.9$ & \\
\hline Birth weight (mean \pm SD (g)) & $1521.25 \pm 381.87$ & $1728.19 \pm 444.38$ & \\
\hline \multicolumn{4}{|l|}{ Fetal growth status } \\
\hline AGA (Appropriate for Gestational Age) & $11 / 16$ & $15 / 16$ & 26 \\
\hline SGA (Small for Gestational Age) & $5 / 16$ & $1 / 16$ & 6 \\
\hline \multicolumn{4}{|l|}{ Place of birth } \\
\hline Saiful Anwar Hospital & $4 / 16$ & $6 / 16$ & 10 \\
\hline Outside Saiful Anwar Hospital & $12 / 16$ & $10 / 16$ & 22 \\
\hline \multicolumn{4}{|l|}{ Apgar score } \\
\hline First minute (mean \pm SD) & $5 \pm 2$ & $4.3 \pm 2.02$ & \\
\hline Fifth minute (mean \pm SD) & $6.6 \pm 2.3$ & $5.8 \pm 2.5$ & \\
\hline \multicolumn{4}{|l|}{ Mode of birth delivery } \\
\hline Vaginal delivery & $10 / 16$ & $10 / 16$ & 20 \\
\hline Abdominal delivery & $6 / 16$ & $6 / 16$ & 12 \\
\hline \multicolumn{4}{|l|}{ Maternal risk factor } \\
\hline Hypertension & 0 & $1 / 16$ & 1 \\
\hline Eclampsia & $2 / 16$ & 0 & 2 \\
\hline Preterm rupture of membrane & $6 / 16$ & $2 / 16$ & 8 \\
\hline \multicolumn{4}{|l|}{ Oxygenation } \\
\hline Nasal cannula & $9 / 16$ & $5 / 16$ & 15 \\
\hline $\begin{array}{l}\text { NCPAP (nasal continuous positive air- } \\
\text { way pressure) }\end{array}$ & $6 / 16$ & $8 / 16$ & 14 \\
\hline Mechanical ventilator & $1 / 16$ & $3 / 16$ & 4 \\
\hline \multicolumn{4}{|l|}{ Outcome } \\
\hline Alive & $16 / 16$ & $12 / 16$ & 28 \\
\hline Died & 0 & $4 / 16$ & 4 \\
\hline
\end{tabular}

showed that the number of male subject and female subject involved in this study was relatively same. This result was in accordance with previous study which showed that the incidence of necrotizing enterocolitis was $55 \%$ in male subjects and $45 \%$ in female subject [8]. Necrotizing enterocolitis occurred earlier in formula feeding group compared with breast milk-formula feeding group. Furthermore, Apgar score both in first and fifth minutes was lower in formula feeding group as compared to breast milk-formula feeding group. This result was in accordance with previous study which demonstrated that early onset necrotizing enterocolitis was associated with respiratory distress [17]. Ventilation support utilization showed no significant differences between groups. Previous study revealed that CPAP (continuous positive airway pressure) and mechanical ventilator utilization was earlier in necrotizing enterocolitis group as compared to digestive distress group [18]
Based on gestational age, there was no significant differences between breast milk-formula feeding group and formula feeding group. Furthermore, birth weight showed that in breast milk-formula feeding group had no significant differences with formula feeding group. Another data also showed similar result in fetal growth status. Previous study had been demonstrated that mean of gestational age 29 (ranged 23 - 33 weeks) was correlated with elevated incidence of necrotizing enterocolitis [17]. Previous study also showed that necrotizing enterocolitis had been occurred in 50\% and $30 \%$ in neonates with birth weight $1,000-$ $1,499 \mathrm{~g}$ and $1,500-1,999 \mathrm{~g}$, respectively [19]. Similarly, 22 years retrospective study showed that the incidence of necrotizing enterocolitis mostly occurred in neonates with birth weight $1,000-1,499 \mathrm{~g}$ [2]. Olariu and colleagues also showed that mean of birth weight in necrotizing enterocolitis group was $1078 \pm 338.72 \mathrm{~g}$ [8]. Ba- 


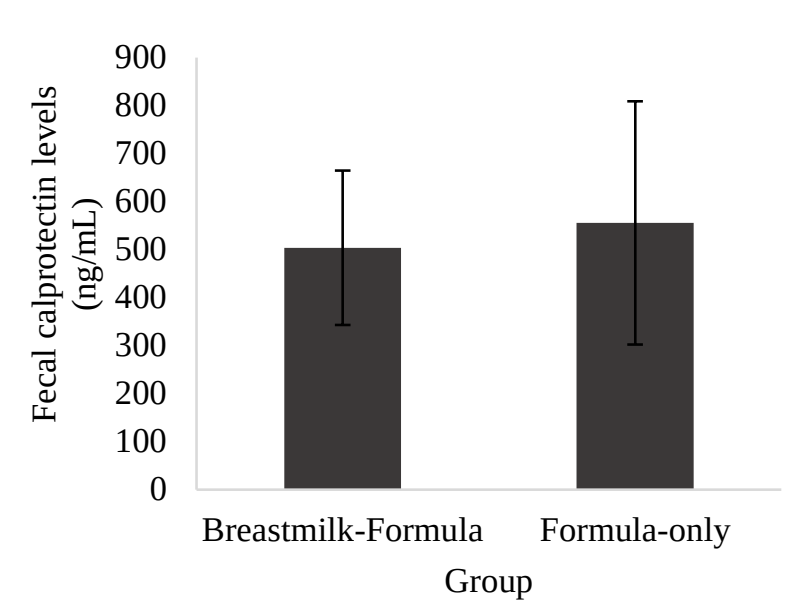

Figure 1. Mean of fecal calprotectin level $(\mathrm{ng} / \mathrm{mL})$ in breast milk-formula feeding group and formula-feeding-only group of preterm and low birth weight neonates with necrotizing enterocolitis

sed on mode of birth delivery, there was no significant differences between groups. Otherwise, previous study showed that abdominal delivery was associated with increased incidence of necrotizing enterocolitis and might be caused by late colonization of normal flora in gastrointestinal tract [20].

Figure 1 showed fecal calprotectin level of combined feeding group and formula-feedingonly group. Comparison test showed that there were no significant statistical differences between groups (independent t-test, $\mathrm{p}=0.9$ ). However, the level of fecal calprotectin in breast milk-formula feeding group ( $508.873 \mathrm{ng} / \mathrm{mL}$ ) was lower as compared to formula-feeding-only group (555.625 $\mathrm{ng} / \mathrm{mL}$ ). Cut-off value for fecal calprotectin level for healthy term and preterm neonates was 145 $\mu \mathrm{g} / \mathrm{g}$ and $332 \mu \mathrm{g} / \mathrm{g}$, respectively [21]. Several studies showed inconsistent finding regarding to correlation of breastfeeding or formula feeding and fecal calprotectin level. Campeotto and Baldassare demonstrated that nutritional type was not associated with calprotectin level in term neonates [22]. Another study showed that calprotectin level was lower in breastfeeding group as compared to formula feeding group [5]. Similarly, Good and colleagues revealed that the incidence of necrotizing enterocolitis was lower in high intake breastfeeding $>50 \%(3 \%)$ as compared to low intake breastfeeding (10\%) [10]. Conversely, Dorosko and Savino showed that calprotectin level was elevated in exclusive breastfeeding group as compared to breast milk-formula and formula-feeding- only group [21]. These controversial results might be caused by uncontrolled bias factor such as gestational age, the amount of formula feeding which more than $50 \%$ breast milk thereby could affect calprotectin level.

\section{Correlation of fecal calprotectin level and out- come}

Correlation study showed that fecal calprotectin level was negatively correlated with patient's outcome (Spearman correlation test, $\mathrm{p}=0.03, \mathrm{r}=$ $0.512)$. It means that low fecal calprotectin level was correlated with high survival rate. Figure 2 showed correlation graph of fecal calprotectin level and patient's outcome. Several studies had been showed correlation of elevated fecal calprotectin and patient's outcome. Several studies revealed that elevated fecal calprotectin could predict necrotizing enterocolitis [15, 22, 23]. Furthermore, in formula feeding group who died, cut-off value of mean fecal calprotectin level was 248.69 $\mathrm{ng} / \mathrm{mL}$. This result was similar with previous study which showed that fecal calprotectin was relatively low in fulminant necrotizing enterocolitis [18]. This condition might be caused by recruitment impairment of granulocyte in intestinal lumen and impaired immune response [18]. Further analysis also confirmed that antimicrobial peptide concentration which possessed chemotactic factor for neutrophil was lower in preterm neonates [18].

This study was designed as observational (cross-sectional) that has a limitation in investigating the causal effect. Because of that, we suggested to do further research which developed experimentally both in vivo or in vitro to investigate the role of breast milk and formula feeding on fecal calprotectin and clinical improvement of necrotizing enterocolitis. Besides that, we suggested to investigate the role of fecal cytokines in preterm and low birth weight neonates with necrotizing enterocolitis and its correlation with breastfeeding. Fecal cytokines which could be detected in fecal sampling for example human $\beta$-defensin 2(hBD2). Other limitation of study was variation of fecal sampling since defecation process which could influence calprotectin level.

\section{Conclusion}

We concluded that fecal calprotectin level in breast milk-formula feeding group was insignificantly lower as compared to formula feeding only 
group in preterm and low birth weight neonates diagnosed with necrotizing enterocolitis. There was negative correlation between fecal calprotectin level and patient's outcome.

\section{Acknowledgment}

We would like to thank the Department of Child Health, Faculty of Medicine, University of Brawijaya/dr. Saiful Anwar General Hospital, Malang, Indonesia for providing the grant to accomplish this research.

\section{References}

1. Neu J, Walker WA (2011) Necrotizing enterocolitis. The New England Journal of Medicine 364: 255-264. doi: 10.1056/NEJMra1005408.

2. Ahle M, Drott P, Andersson RE (2013) Epidemiology and trends of necrotizing enterocolitis in Sweden: 1987-2009. Pediatrics 132 (2): e443 - e451. doi:10.1542/peds.2012-3847.

3. Henry MCW, Moss RL (2009) Necrotizing enterocolitis. Annual Review Medicine 60: 111 - 124. doi: 10.1146/annurev.med.60.050207.092824.

4. Maheshwari A, Corbin L, Schelonka R (2011) Neonatal necrotizing enterocolitis. Research and Reports in Neonatology 1: 39 - 53. doi: 10.2147/RRN.S23459.

5. Gordon P, Christensen R, Weitkamp JH, Maheshwari A (2012) Mapping the new world of necrotizing enterocolitis (NEC): Review and opinion. The E-Journal of Neonatology Research 2 (4): $145-172$.

6. Chu A, Hageman JR, Caplan MS (2013) Necrotizing enterocolitis: Predictive markers and preventive strategies. Neoreviews 14 (3): e113 - e120. doi: 10.1542/neo.14-3-e113.

7. Grave GD, Nelson SA, Walker WA et al. (2007) New therapies and preventive approaches for necrotizing enterocolitis: Report of a research planning workshop. Pediatric Research 62: $510-$ 514. doi: 10.1203/PDR.0b013e318142580a.

8. Olariu L, Olariu G, Ognean L et al. (2014) Necrotizing enterocolitis in preterm infants with gestational age $<32$ weeks in Rumania: Incidence and risk factors. Jurnalul Pediatrului 17: 36 41.

9. Hunter CJ, Upperman JS, Ford HR, Camerini V (2008) Understanding the susceptibility of the premature infant to necrotizing enterocolitis (Nec). Pediatric Research 63: 117 - 123. doi: 10.1203/PDR.0b013e31815ed64c.

10. Good M, Sodhi CP, Hackam DJ (2014) Evidence-Based feeding strategies before and after the development of necrotizing enterocolitis. Expert Review of Clinical Immunology 10 (7): 875 884. doi: 10.1586/1744666X.2014.913481.
11. Young C, Sharma R, Handfield M et al. (2009) Biomarkers for infants at risk for necrotizing enterocolitis: Clues to prevention?. Pediatric Research 65: 91r - 97r. doi: 10.1203/PDR.0b013e31819dba7d.

12. Markel TA, Engelstad H, Poindexter BB (2014) Predicting disease severity of necrotizing enterocolitis: how to identify infants for future novel therapies. Journal of Clinical Neonatology 3 (1): 1 - 9. doi: 10.4103/2249-4847.128717.

13. Ng PC (2014) Biomarkers of necrotising enterocolitis. Seminars in Fetal and Neonatal Medicine 19 (1): 33 - 38. doi: 10.1016/j.siny.2013.09.002.

14. Dhas B, Bhat V, Gane B (2012) Role of calprotectin in infection and inflammation. Current Pediatric Research 16 (2): 83 - 94.

15. Aydemir O, Aydemir C, Sarikabadayi YU et al. (2012) Fecal calprotectin levels are increased in infants with necrotizing enterocolitis. Journal of Maternal-Fetal and Neonatal Medicine 25 (11): 2237 - 2241. doi: 10.3109/14767058.2012.684172.

16. Vaos G, Kostakis ID, Zavras N, Chatzemichael A (2013) The Role of calprotectin in pediatric disease. Biomed Research International: 542363. doi: 10.1155/2013/542363.

17. Stout G, Lamber DK, Baer VL et al. (2008) Necrotizing enterocolitis during the first week of life. Journal of Perinatology 28: 556 - 560. doi: 10.1038/jp.2008.36

18. Zoppelli L, Guttel C, Bittrich HJ et al. (2012) Fecal calprotecti concentration in premature infants have a lower limit and show postnatal and gestational age dependence. Neonatology 102: 68 - 74. doi: 10.1159/000337841.

19. Sidauruk RJM, Amir I, Kadim M, Said M (2014) Faktor risiko yang mempengaruhi kolonisasi mikroflora saluran cerna neonatus kurang bulan dengan enterokolitis nekrotikan. Sari Pediatri 15 (6): 353 - 360. doi: 10.14238/sp15.6.2014.353-60.

20. Josefsson S, Bunn SK, Domellöf M (2007) Fecal calprotectin in very low birth weight infants. Journal of Pediatric Gastroenterology and Nutrition 44 (4): 407 - 413 . doi: 10.1097/MPG.0b013e3180320643.

21. Kapel N, Campeotto F, Kalach N et al. (2010) Fecal calprotectin in term and preterm neonates. Journal of Gastroenterology Hepatology and Nutrition 51 (5): 542 - 547. doi: 10.1097/MPG.0b013e3181e2ad72.

22. Campeotto F, Baldassarre M, Butel MJ et al. (2009) Fecal calprotectin: Cutoff values for identifying intestinal distress in preterm infants. Journal of Pediatric Gastroenterology and Nutrition 48 (4): 507 - 510. doi: 10.1097/MPG.0b013e318186c4a6.

23. El Frargy MS, Hassan AM (2014) The Effect of probiotics supplementation on fecal calprotectin as an early marker of neonatal enteropathy. Journal of American Science 10 (8): 209 - 213. 
This page is intentionally left blank. 